\title{
Hearing sub-Saharan African voices in bioethics
}

\author{
Kevin Gary Behrens ${ }^{1}$
}

At the time of writing this introduction, universities in South Africa are all but paralysed by on-going student protests. Under what is being called the 'Fees Must Fall' movement, student activists across the country are demanding free higher education for all. But, the protests are not only about the financing of education. The consistent call of the protesters has been for 'free, decolonised education'. Underlying the current unrest is a broad sense of frustration and even anger that more than two decades since the dawn of democracy in South Africa, little progress has been made towards transforming the higher education landscape.

Institutions have been slow to even begin addressing the question of reforming the academic curriculum to be more responsive to local and regional priorities and realities. The demographic profile of the academic staff at universities does not come close to being representative of the population: there are not nearly enough black academics. In many faculties and departments, the content of the curriculum is hardly distinguishable from what is taught in universities in Europe or America. Key works of African scholars in many fields have not found their way into the canon of referenced literature. Indigenous knowledge is given scant attention, and African epistemological, ontological, ethical, and metaphysical notions are often overlooked in favour of their more familiar and influential Western counterparts. Broadly, what the student movement understands as 'colonised' education seems to include the following:

- education that continues to be dominated by the methods, theories and presuppositions of the colonial masters who first created the universities in Africa;

Kevin Gary Behrens

Kevin.Behrens@wits.ac.za

1 Steve Biko Centre for Bioethics, University of the Witwatersrand, 1 Jan Smuts Avenue, Braamfontein, Johannesburg 2000, South Africa 
- education that fails to give sufficient attention to indigenous knowledge, values, and theoretical conceptions;

- education that is not contextually relevant and responsive to local needs.

The frustration of South African students with the untransformed nature of the higher education landscape in their country draws attention to a deeper and pervasive problem for the African continent, particularly sub-Saharan Africa. Scholarship across Africa is still largely dominated by Western thought and a canon that has been inherited from the colonial academy. In one of the articles in this special issue, Godfrey Tangwa reminds us of the painful period in the 1970s and 1980s when African philosophy was under siege by those who thought that the very notion of such a thing as African philosophy was unthinkable [1]. For decades African philosophers were required to expend much of their energy merely justifying their existence. Fortunately that debate is now largely behind us. African philosophy has become established as a broad philosophical tradition in its own right. However, during discussions about the state of African philosophy and the curriculum at a number of recent conferences, it became evident that African thought is still given short shrift in many institutions of learning across the continent. Too few courses in African philosophy are taught, and too little has been done to mainstream African scholarship and ideas into the canon and the curriculum.

This is equally true when it comes to bioethics as a field of applied ethics or moral philosophy. Even a cursory review of the bioethics literature from subSaharan Africa quickly leads to the realisation that almost all of our ethical discourse is grounded in Western moral theories and ethics principles. Even those African theorists who have addressed contextually pertinent bioethical issues affecting the people of this continent have principally relied on conventional moral notions imported from the West. Bioethics in Africa remains dominated by the principlism espoused by Beauchamp and Childress [2], and the familiar moral theoretical frameworks of utilitarianism, deontology, care ethics, virtue ethics, and the like. Very little work has been done that considers ethical issues in the health sciences through the lens of indigenous African moral thought or values. Only a very small number of African theorists have published works of this type.

Yet, African philosophy and ethics are fields that are growing rapidly. In Southern Africa, in particular, more and more work has been coming out on Ubuntu as a moral framework. There are a number of salient ethical notions seemingly shared by many of Africa's people that can contribute to and enrich our ethical discourse. As Godfrey Tangwa pointed out in as far back as 1996:

From western Christianity through western languages and education, to western systems of thought, philosophies and fashions, Africans have honestly and enthusiastically got into the spirit of things western. In the process, Africans have benefitted from western culture and used it to enrich their indigenous cultures. But, unfortunately, in so doing, Africans have neglected some vital aspects of their own indigenous cultures which could, in turn, have helped to humanize and enrich western culture. [3]. 
This challenge remains as relevant today as it was then. There is a wealth of subSaharan ethical thought that has yet to be drawn on by bioethicists. The articles in this special issue represent part of the ongoing project of developing work in bioethics that is responsive to specifically African needs and priorities in health care and research, and that considers bioethical issues through the lens of sub-Saharan moral notions or thought.

There are many reasons why this project is important. One of the most obvious is that we cannot fully appreciate our moral obligations towards others unless we come to some understanding of what their interests and values are, of what matters to them in their lived experience. Ethical codes and guidelines for ethical clinical practice, research, health policy, and public health interventions that are informed only by Western moral theories and values fail to acknowledge this. The voice of Africans needs to be heard in this discourse. Another reason is that we are more likely to obtain buy-in to moral values that are already familiar to people. If African researchers are able to ground their moral obligations to their participants and society in general on indigenous ethical notions, such as harmony, communal solidarity, Ubuntu, etc., then they are more likely to take on their obligations and responsibilities. Most importantly, perhaps, is that this project can go some way to restoring dignity to the people of Africa. Given how African culture and beliefs were denigrated in our colonial past, it may help to restore a sense of pride and ownership of ethical values, that is, when Africans feel that their voices are being heard and that they have much to contribute to the ongoing discourse on bioethics on this continent.

The articles included in this special issue were presented at an international conference jointly hosted by the Steve Biko Centre for Bioethics, University of the Witwatersrand, and the Philosophy Department, University of Johannesburg, in December 2015. The title of the conference was, 'Giving a Voice to African Thought in Medical Research Ethics'. Since the main sponsor was the South African Medical Research Council, the focus of the conference was on research ethics. However, the organizing committee decided early on that quality papers dealing with any kind of issue in bioethics of relevance to the African context, or through the lens African thought, would be welcomed. The papers selected for this issue reflect this, as their focus is not constrained to medical research ethics.

The first article in this issue was presented by Godfrey Tangwa as the keynote address at the conference, and was entitled 'Giving voice to African thought in medical research ethics' [1]. Tangwa argues that African thought is marginalized in the global medical research ethics discourse, which remains dominated by Western conceptions, theories, frameworks, and paradigms. This he considers to be extremely unfortunate since 'reality and human experience are too vast and too diverse to be captured by one culture or conceptual paradigm, be it globally dominant or not.' In other words, he worries that medical research ethics is impoverished as a result of this marginalization. Tangwa argues that the lack of attention given to African thought in the global discourse is not accidental. Rather, he claims, it is a function of 'eurocentric hegemony derived from colonialism and colonial indoctrination cum proselytization.' Despite this rather gloomy judgment, Tangwa seeks to offer a way forward in terms of a general framework of seven 
theses that he believes can help redress the situation. He thus holds out hope that the future of medical research ethics may yet be enriched by African voices.

Thaddeus Metz addresses the issue of ancillary care obligations in medical research [4]. That is, he is concerned to explore what sorts of ethical obligations (if any) researchers have towards their participants with respect to providing aid to them for reasons other than seeking to ensure that they are not harmed or to compensating them when they are harmed as a result of their participation in a research project. Noting that the debate about such possible obligations is underdeveloped and that consensus is elusive, he sets out to articulate a theory that could best account for such obligations. Drawing on his existing work on a moral theory grounded in salient sub-Saharan moral notions of communion, identity, and solidarity, he proposes an account of ancillary care obligations understood through the lens of African thought. He argues that his preferred relational approach provides a better account of ancillary obligations than the existing individualist approaches in the literature.

Christopher Wareham identifies three common tenets in African moral theories: relationality, community, and partiality [5]. In his contribution to this issue, he focuses his attention on the partiality tenet, which is supported by many subSaharan accounts of morality. Roughly, the tenet holds that we ought to give preference to those with whom we have close relationships, such as family and friends. This view stands in strong opposition to the impartiality inherent in many Western moral theories. In contrast to the view held by many Africanists, namely, that the partiality of African moral perspectives constitutes an advantage over alternative moral theories, Wareham proposes and defends an impartial African medical ethics. In particular, he seeks to defend the claim that approaches to African ethics that embrace the partiality tenet lead to undesirable conclusions, especially when applied to cases in medical ethics and considered in the light of distributive justice. He argues that his preferred impartial African-inspired medical ethics, although not yet fully developed, represents a novel possibility worthy of further consideration.

Nyasha Chingore-Munazvo, Katherine Furman, Annabel Raw, and Mariette Slabbert, in their article, address important concerns regarding the notion of informed consent and its application in an African context [6]. The focus of their discussion is a 2014 judgment of the Supreme Court of Namibia, Government of the Republic of Namibia v LM and Others [7]. In this case, three HIV-positive women sought compensation from the government for having been sterilized without proper informed consent. Chingore-Munazvo et al. provide a careful interpretation and analysis of the court's ruling, unpacking some of the ways in which established ideas about informed consent are challenged in the southern African context. In particular, they show how what we understand as 'necessary capacity' and what it means to be 'informed' need to be reconsidered in a context in which power dynamics have a profoundly disruptive impact on the communicative process necessary for true informed consent to be obtained. Their article also highlights some of the many ways in which HIV-positive women in sub-Saharan Africa are especially vulnerable. 
The focus of the final article in this collection is on another especially vulnerable group in Africa: persons with albinism (PWA) [8]. Elvis Imafidon points out that while albinism is a public health concern globally, it is of particular concern in Africa, where the social stigma experienced by PWA is pervasive and often results in mistreatment. He identifies two reasons for this. The first is an African ontology that sees 'albinism as an alterity or otherness' and the second is what he sees as an African preference for a narrowly focused, culturally group-based 'ethical point of view' over a more universalist, non-culturally specific 'moral point of view'. Imafidon concludes that a major shift in how PWA are perceived in Africa is a prerequisite to enable necessary reform in policy, law, health care, and the like.

The five articles in this issue contribute to the ongoing project of giving a voice to African thought in bioethics. It is hoped that they are able to go some way towards enriching the discourse.

Acknowledgements The articles in this issue were originally presented as papers at an international conference held in Johannesburg, South Africa, in December 2016, entitled 'Giving a Voice to African Thought in Medical Research Ethics'. The conference was co-hosted by the Steve Biko Centre for Bioethics, University of the Witwatersrand, and the Department of Philosophy, University of Johannesburg. The organizing committee would like to thank the South African Medical Research Council for their generous grant, which made the conference possible. They are also grateful to Thaddeus Metz, from the University of Johannesburg, for additional funding. I would like to thank the following individuals for their support of this project in various ways: Thaddeus Metz, Godfrey Tangwa, Ames Dhai, Chris Wareham, Tebogo Dithung, and Samkelo Nsibande. Thanks also to all of the speakers and other participants at the conference and to those who were prepared to act as reviewers of the papers submitted for this issue. Lastly, I wish to thank Daniel Sulmasy, editor of Theoretical Medicine and Bioethics, for his willingness to consider this special issue and for his support throughout.

\section{References}

1. Tangwa, Godfrey B. 2017. Giving voice to African thought in medical research ethics. Theoretical Medicine and Bioethics. doi:10.1007/s11017-017-9402-3.

2. Beauchamp, Tom L., and James F. Childress. 2013. Principles of biomedical ethics, 7 th ed. New York: Oxford University Press.

3. Tangwa, Godfrey B. 1996. Bioethics: An African perspective. Bioethics 10 (3): 183-200.

4. Metz, Thaddeus. 2017. Ancillary care obligations in light of an African bioethic: From entrustment to communion. Theoretical Medicine and Bioethics. doi:10.1007/s11017-017-9404-1.

5. Wareham, Christopher. 2017. Partiality and distributive justice in African bioethics. Theoretical Medicine and Bioethics. doi:10.1007/s11017-017-9401-4.

6. Chingore-Munazvo, Nyasha, Katherine Furman, Annabel Raw, and Mariette Slabbert. 2017. Chronicles of communication and power: Informed consent to sterilisation in the Namibian Supreme Court's LM judgment of 2015. Theoretical Medicine and Bioethics. doi:10.1007/s11017-017-9405-0.

7. Government of the Republic of Namibia v LM and Others (SA 49/2012). 2014. NASC 19. http://www. saflii.org/na/cases/NASC/2014/19.html. Accessed Mar 12017.

8. Imafidon, Elvis. 2017. Dealing with the other between the ethical and the moral: Albinism on the African continent. Theoretical Medicine and Bioethics. doi:10.1007/s11017-017-9403-2. 